\title{
Implications of COVID-19 Lockdown on Child Preparedness among Rwandan Families
}

\author{
*Muhayimana Alice ${ }^{1,2}$, Mukamana Donatilla ${ }^{1}$, Ndayisenga Jean Pierre ${ }^{1,2}$, Tengera Olive ${ }^{1,2}$, \\ Murekezi Josephine $^{2,3}$, Uwacu Josette ${ }^{2,4}$, Eugenie Mbabazi ${ }^{2,3}$, Musabe Joyce ${ }^{5}$
}

\begin{abstract}
The world is currently facing the fatal viral pandemic called coronavirus disease 2019 (COVID-19), earlier named 2019-novel coronavirus (2019-nCoV). Every country of the world keeps responding to the challenges posed by covid-19 in all aspects of human endeavour with high demand and burden on health care. The report of the first case in Rwanda on 14th March 2020 was accompanied by actions to drive control measures by the government of Rwanda importantly to prevent the spread of COVID-19. Those measures included education on personal preventive behaviours, social distancing and restricting the movement of people locally, nationally and internationally resulting to lockdown that allowed only essential services. Lockdown has particularly affected Rwandan families with pregnant mothers in the context of childbirth preparation in different aspects. This review paper articulates the possible various dimensions of influence of the COVID-19 lockdown on birth preparedness by families and the possible maternal and neonatal health adverse outcomes that may be associated. This is with the intention of helping health care providers and other stakeholders anticipate, track and prepare for appropriate mitigation to reduce maternal-neonatal morbidity and mortality.
\end{abstract}

\footnotetext{
*Corresponding Author

Muhayimana Alice

http://orcid.org/0000-0002-5318-497X

E-Mail: hayiali@yahoo.fr.
}

${ }^{1}$ School of Nursing and Midwifery at the University of Rwanda, Kigali, Rwanda. ${ }^{2}$ Rwanda Association of Midwives, Kigali, Rwanda. ${ }^{3}$ King Faisal Hospital, Kigali, Rwanda. ${ }^{4}$ Muhima District Hospital, Kigali, Rwanda. ${ }^{5}$ Training Support, Access Model for Maternal Newborn Child Health Project-Rwanda. 


\title{
Implications du verrouillage de COVID-19 sur la préparation des enfants dans les familles Rwandaises
}

\author{
*Muhayimana Alice ${ }^{1,2}$, Mukamana Donatilla ${ }^{1}$, Ndayisenga Jean Pierre ${ }^{1,2}$, Tengera Olive ${ }^{1,2}$, \\ Murekezi Josephine $^{2,3}$, Uwacu Josette ${ }^{2,4}$, Eugenie Mbabazi ${ }^{2,3}$, Musabe Joyce ${ }^{5}$
}

\section{Résumé}

Le monde est actuellement confronté à la pandémie virale mortelle appelée maladie à coronavirus 2019 (COVID-19), précédemment appelée 2019-nouveau coronavirus (2019-nCoV). Chaque pays du monde continue de répondre aux défis posés par le Covid-19 dans tous les aspects de l'activité humaine avec une forte demande et un fardeau sur les soins de santé. Le rapport du premier cas au Rwanda le $14^{\text {e }}$ mars 2020 a été accompagné d'actions à conduire des mesures de contrôle par le gouvernement du Rwanda important pour prévenir la propagation de Covid-19. Ces mesures comprenaient une éducation sur les comportements personnels de prévention, la distanciation sociale et la restriction de la circulation des personnes aux niveaux local, national et international, entraînant un verrouillage qui n'autorisait que les services essentiels. Le verrouillage a particulièrement affecté les familles Rwandaises de mères enceintes dans le cadre de la préparation à l'accouchement sous différents aspects. Cet article de synthèse articule les différentes dimensions possibles de l'influence du verrouillage du COVID-19 sur la préparation à la naissance des familles et les éventuels effets indésirables sur la santé maternelle et néonatale qui peuvent être associés. Ceci dans le but d'aider les prestataires de soins de santé et les autres parties prenantes à anticiper, suivre et préparer des mesures d'atténuation appropriées pour réduire la morbidité et la mortalité materné-néonatales.

\author{
*Corresponding Author \\ Muhayimana Alice \\ http://orcid.org/0000-0002-5318-497X \\ E-Mail: hayiali@yahoo.fr.
}

${ }^{1}$ School of Nursing and Midwifery at the University of Rwanda, Kigali, Rwanda. ${ }^{2}$ Rwanda Association of Midwives, Kigali, Rwanda. ${ }^{3}$ King Faisal Hospital, Kigali, Rwanda. ${ }^{4}$ Muhima District Hospital, Kigali, Rwanda. ${ }^{5}$ Training Support, Access Model for Maternal Newborn Child Health Project-Rwanda. 


\section{INTRODUCTION}

Coronavirus disease 2019 (COVID-19), was discovered in Wuhan city from the Hubei province of China. The disease spread like wildfire across China and took the lives of hundreds. The COVID-19 progressed and became a global emergency crisis and was declared a pandemic by the World Health Organization (WHO) on $11^{\text {th }}$ March $2020(1,2,3)$. From this time, every country has taken its approach to enforce the measures globally divulgated as means to reduce the spread of COVID-19 from one country to another and inside the country.

Coronavirus disease 2019 (COVID-19), was discovered in Wuhan city from the Hubei province of China. The disease spread like wildfire across China and took the lives of hundreds. The COVID-19 progressed and became a global emergency crisis and was declared a pandemic by the World Health Organization (WHO) on $11^{\text {th }}$ March $2020(1,2,3)$. From this time, every country has taken its approach to enforce the measures globally divulgated as means to reduce the spread of COVID-19 from one country to another and inside the country.

The COVID-19 shifted from Asia, to America and Africa continents rapidly. From this time global preventive measures across continents were taken. According to WHO (12) these preventive strategies comprise the closure of borders, halting airline operations, and social distancing, restricting the movement of people. In addition, people who were affected were isolated, and those who were exposed were quarantined. Furthermore, hygienic measures were taken like fumigation, ongoing hands sanitizing, frequent hands washing, and instructing the population to avoid touching their face $(4,13)$.

Those preventive measures affected the life of pregnant women and their families differently, particularly about birth preparedness. Therefore, the purpose of this paper is to critically analyse the impact of COVID-19 on birth preparedness among Rwandan families during the lockdown period. It affected the culturally centred care around childbirth, and the standard of care recommended to the mothers. Women's rights to deliver at desired health facilities and choose preferred skilled attendants were limited and even deprived for many. Family income decreased, which potentially impacted nutrition and the general health of the mother and unborn baby. Social activities involving friends, relatives, and community to prepare mothers financially and psychologically for childbirth was limited.

\section{The Government of Rwanda's Response to COVID-19}

The first case of COVID-19 appeared in Rwanda on 14th March 2020 (5); two months later, on 14th May 2020, the country counted 287 of people affected with COVID-19, while 168 recovered and 119 were still sick with 0 death (6). Therefore, from this time, the new cases were increasing day by day. To address COVID-19 pandemic issues, the government of Rwanda initiated all preventive measures to stop or mitigate the quick transmission of the virus. From $21^{\text {st }}$ March, Rwanda has started the quarantine and lockdown, where everyone living in Rwanda was advised to stay home. The lockdown was part of the effort to combat the coronavirus (COVID-19), which has ravaged the world as well as Rwanda. During this period of lockdown, only essential activities were allowed for Rwanda countrywide. Those activities were among others like seeking medical care, selling foodstuffs and other essential groceries, public transportation was permitted for those providing essential services. Rwandan communities, in general, were affected by these measures and specifically for pregnant mothers and their families. For instance, it has become difficult for Rwandan families of pregnant women to make preparations for birth according to the usual Rwandan culture practices. As a consequence of COVID-19 pandemic cultural and normal ways of birth preparedness including having a supporting person during labour, choosing the preferred birth facility and emotional and buying essential delivery kits were not easily possible during the lockdown period. Therefore, this affected negative many Rwandan family and could results to mental health problem for both mothers and their families during and after delivery.

\section{Childbirth in Rwandan Culture}

Around the globe, different cultures have their ways of welcoming a newborn baby. In Rwanda, the preparation of the baby is different from rural to urban regions. In Rwanda's culture, childbirth is a family affair involving the extended family. Many years ago, there was a misconception that discouraged mothers from buying unborn babies' clothes. Therefore, families believe that if they buy baby's clothes, the baby will not live. From these beliefs, some women are used to buying the clothes immediately after giving birth and realizing that the baby is alive. Also, to prepare for birth, parents should store foodstuff or enough money to be consumed at birth "guhemba umubyeyi". According 
to the Rwandan culture, after the mother has given birth, the extended family, even the community, come to support the mother; some stay with her at least for one month. The time is not specific, but the mother should be helped for domestic duties until when she can work on herself. Unfortunately, as a results of applying COVID-19 like social distancing and stay home, the family involvement in the childbirth experience was significantly distorted during covid19 lockdown and could result to poor birthing experiences for women and their families.

Currently, in the Rwandan context, there is a difference between urban and rural areas. In an urban area, the inhabitants have adopted some aspects of the western lifestyles while in the rural area, keep the tradition of their ancestors. Urban families tend to prepare the name to give to the baby before birth. Most of the time, they give their children the same family name. On the other hand, traditionally, a baby does not have any name at birth, all babies are called "Buhinja" it is on the eighth day of birth that Rwandan children are formally named by family members, where the family organizes a big party in which children of the surrounding community and family members are all invited to attend.

In this child naming culture ceremony, each child attending the ceremony is expected to suggest a name and is among those names that the parents will choose an official name for their baby. However, recently the government of Rwanda has decided that newborns have to be registered at birth; therefore, parents should name their babies at birth or before. Nevertheless, during the COVID-19 lockdown, the service in charge of birth registration was unable to operate while mothers were still in the health facilities. In addition, there was no known alternative options for families to keep registration of these new born babies using technology like mobile phones or computers on their own at their homes. Therefore, this was a big challenge to many families living in both rural an urban area of Rwanda as not being registered for the infant could derivates them to the access to health care insurance and also affected the new infants' rights of to be legally registered immediately after birth.

\section{Challenges about Birth Preparedness during the COVID-19 Lockdown Period}

In general, the COVID-19 lockdown has impacted all domains of family life, specifically, pregnant mothers were more affected (11). It impacted on women's rights, family's income, health, nutrition, psychosocial activities. The birth preparation plan, according to WHO recommendations, was all affected. WHO recommends pregnant mothers during the third trimester to think and make a choice on the desired facility to give birth and the preferred skilled birth attendant. In addition, mothers should think of the closest facility for birth just in case of a complication, money for any expenses during childbirth should be kept aside. Women are advised to prepare on time supplies and materials necessary to bring to the facility, look for a birth companion, identify someone to look after the home, and book transport to a birth facility for birth (7).

Keeping money for expenses around childbirth was a big challenge that affected birth preparedness among Rwandan families during the COVID-19 lockdown period. COVID-19 lockdown has challenged different life aspects and the literature reported that it has tremendously affected the global economy, including Rwanda (4). During the lockdown period, people were working from home while others had lost their jobs. Consequently, the decrease of the economy also affected the health of family members, so families were not financially able to store foodstuff to be consumed at around childbirth and later. Furthermore, mothers could not prepare enough pocket money to cover all expenses at the time of birth. Specifically, the nutrition of mothers while pregnant and after birth was affected. Hence, nutrition is vital for health outcomes for both mother and baby was affected. Evidence shows that lack of a balanced diet while pregnant or after birth leads to low birth weight, a decrease of breastmilk, and child stunting (8).

\section{Preparation of Materials and Supplies to Bring to the Health Facility}

As during COVID-19 lockdown, most mothers getting ready with supplies and materials was tricky as businesses were down. Mothers from rural areas where culture is still a norm were mostly affected. The clothes shops were closed all over the country; families could not shop baby linen and other essential for birth and newborns. The majority of mothers were not ready with supplies and materials to bring to the health facilities. Midwives were challenged to get linen for the newborn babies; therefore, midwives have covered the situation by taking clothes stores. However, the store was empty after a short period. A study done in Rwanda in 2018 about birth 
preparedness reported that nulliparous women were better prepared than multiparous mothers (9). However, during the COVID-19 lockdown, while most nulliparous mothers came to deliver without any baby clothes, most of the multiparous mothers brought clothes or materials used for the previous baby.

\section{Attendance of Desired Birthing Health Facility}

Unlike in confinement, crossing town to town or country to country was not allowed, therefore mothers were deprived of attending the health facility of their choice during childbirth. Hence, the only choice for mothers was to deliver at the nearest health facility. In addition, the majority of mothers walked to get to the birthing facility. Fortunately, in Rwanda, there is relatively widespread availability of health facilities where most women have to use less than one hour from home to health facilities (9). Mothers who had planned to deliver outside the country had simply a single choice of going to in-country health facilities; therefore, they were happy with the services provided to them, and the care given to them was better than expected. On the other hand, during COVID-19 lockdown, mothers with better financial means, have attended the health facilities which provide meals and other materials. Therefore, above facilities were full even overwhelmed because they are few within the country.

\section{Transportation of Mothers}

It was a big challenge for mothers to get transport means to health facilities quickly. Even for mothers who have delivered and been discharged from birthing facilities, going back home was a big issue due to limited vehicles as well as financial resources. When the time of going back home came, some mothers walked cradling their babies, while others stayed several days in the hospital waiting for the means of transportation.

During COVID-19 lockdown, in case of complications arose, the process of a hospital to hospital transfers was challenged by insufficient ambulance and new means of payment because it was advised to use cashless in order to avoid the spread of disease. At the district hospital, the number of existing ambulances was decreased because one ambulance was strictly reserved for patients with COVID-19. Concerning payment, women had experienced delays due to an abrupt shift of the payment system from cash to digital means.

\section{Birth Companionship}

Another essential element of birth preparedness is to identify a birth companion person. Besides that, designating someone else to stay home looking after children was needed, but it was not easy to find them during confinement. In Rwandan culture, mothers used to be accompanied by the entire family, including her mother, mother in law, sisters, and others. Birth companionship during labor and childbirth process has a good impact on the mother's emotional support. During COVID-19, lockdown, mothers who delivered without being accompanied, were anxious, felt lonely, abandoned, and disempowered.

Due to the COVID-19 lockdown period, getting a birth companion became almost impossible for some Rwandan families due to movement restriction. Even mothers were not allowed to bring birth companions in delivery rooms and theatre. Companions were being denied to come from a home with mothers or denied at the hospital. As a result, a large number of mothers were laboring and giving birth without someone around. Only the husband was allowed, but he was obliged to stay at the hospital until his wife's discharge. Husbands have suffered from tiredness and sleepless nights. The literature argues that to avoid transmission of COVID-19, birth companionship has to be limited in labor wards (10). Consequently, the lack of birth partners negatively affected the labor support that women were supposed to receive from their relatives (10).

Due to movement restrictions, families were not allowed to move from home to the health facilities to bring food and drinks to the mothers. The restaurants were closed everywhere, mothers were not allowed to have companions to help look for something to eat, and midwives were busier than ever, dealing with deliveries and COVID 19 prevention measures. Mothers were laboring without nourishment to increase energy. At the beginning of lockdown, it was a big challenge, but a few days later, the hospital arranged to get food for mothers. However, while distributing food, mothers were the ones to queue on the food line.

\section{The Impact of COVID-19 on Cultural and Social Events around Childbirth within the Extended Family}

In Rwanda, pregnancy and preparation for childbirth are moments of joy not only for the nuclear family but to the large one, even to the whole community. 
Usually, the mother is being cared for by the whole family members in general, including grandmothers and mothers in law. The care is provided by her own family, in-laws family, even the entire community. The family assists the mother in preparing all the necessary materials for birth. Unfortunately, during the COVID-19 lockdown, the nuclear family was alone to do all preparation and were physically separated from their extended families.

Social activities have been affected during that period. Actually, in urban areas, before the pandemic, friends, relatives of the expectant mother used to prepare a ceremony called "baby shower". The purpose of the ceremony was to support the mother psychologically and financially. During this ceremony, gifts of clothes, equipment, and supplies for both baby and mother or money were offered. In addition, psychological support is provided by an experienced mother to prepare the mother for the day of labor and childbirth. This event is a sign of love, care, harmony, and friendship to the expectant mother. Consequent to COVID-19, crowded people were not allowed, thus making these events impossible to happen.

In Rwandan culture, after childbirth, male partners used to celebrate by having some drinks with friends and relatives. Unfortunately, during the lockdown, social distancing rules did not allow them to do so. However, the good thing is that during that specific period, families stayed closer, we may even believe that husbands had enough time to help their wives during the preparation of birth, which is a positive thing.

Childbirth is also celebrated by visiting and providing all kinds of gifts to the family. In addition, the mother is being helped by relatives and friends for domestic work until she gets strong enough to fulfil all home duties. In fact, after giving birth, the mother starts receiving visitors while in the hospital and even after being discharged. Culturally mothers would not do so much but would be handed everything they may need to facilitate their healing and, at the same time, acclimate to the newborn. However, during this lockdown, these events were not possible, and mothers and husbands for those who are married were alone and did all activities on their own.

\section{Lesson learned and recommendations.}

Measures taken have to put into consideration cultural and societal norms and beliefs. Some special conditions like pregnant women have to be assessed carefully and prioritized. Consequently, midwives discovered that more effort should be put in educating pregnant women during antenatal consultation, to have on-time baby clothes. In addition, Rwandan people's beliefs rooted in culture should be evolved. However, we realize that the solidarity among mothers was strengthened. It was noted that these mothers were volunteering to share foodstuff and other needed items with their peers. Midwives took a step and arranged themselves to get drinks and food for mothers in labor and clothes for newborn babies.

Furthermore, in preventing transmission of the virus, midwives have been emergently trained in the use of personal protective equipment. Besides this, mothers were being tested for COVID-19 before being discharged from the birthing facilities. Taken measures were implemented; however, in some situations, the implementation of those preventive measures violated pregnant mothers' rights and their families. Also, there were no clear guidelines for pregnant mothers and their families to access essential services. It would be of great advantage if policymakers would refer to multidimensional perspectives that consider different options in different emergencies.

\section{CONCLUSION}

Birth preparedness and childbirth during the COVID-19 lockdown period was a hard time for families with pregnant mothers. During confinement, family-centered care was affected, but on the other side, we believe that it was an opportunity for nuclear families to be reunified more than ever. The COVID-19 was an unprecedented global crisis; however, the government of Rwanda made all efforts to protect its population including mothers and healthcare providers whereby until $8^{\text {th }}$ June 2020 there was no pregnant mother or midwives who died from COVID- 19.

\section{ACKNOWLEDGMENT}

We acknowledge the University of Rwanda, School of Nursing and Midwifery for allocating time to write this paper.

Funding: None declared

Ethical Clearance: None declared

Conflict of Interest: None declared 
Declaration of Interests: No competing financial interests is declared.

AM was supported by the Consortium for Advanced Research training in Africa (CARTA). CARTA is jointly led by the African Population and Health Research Center and the University of the Witwatersrand and funded by the Carnegie Corporation of New York (Grant No-B 8606.RO2), Sida (Grant No 54100029), the DELTAS Africa initiative (Grant No: 107768/z/15/z). The DELTAS Africa initiative is an independent funding scheme of the African Academy of Sciences (AAS)'s Alliance for Accelerating Excellence in Science in Africa (AESA) and supported by the New partnership for Africa's Development Planning and Coordinating Agency (NEPAD Agency) with funding from the Welcome Trust (UK) and the UK government. The statements made and views expressed are solely the responsibility of the fellow.

\section{REFERENCES}

1. World Health Organization. WHO announces COVID-19 outbreak a pandemic. World Health Organization [Internet]. 2020 Mar 12.Available from: http://www.euro.who.int/en/healthtopics/health-emergencies/coronavirus-covid19/news/news/2020/3/who-announces-covid19-outbreak-a-pandemi

2. Ohia C, Bakarey AS, Ahmad T. COVID-19 and Nigeria: Putting the realities in context. International Journal of Infectious Diseases. 2020 Apr 27.

3. Cucinotta D, Vanelli M. WHO declares COVID19 a pandemic. Acta bio-medica: Atenei Parmensis. 2020 Mar 19;91(1):157-60.

4. Bizoza A, Sibomana S. Indicative SocioEconomic Impacts of the Novel Coronavirus (Covid-19) Outbreak in Eastern Africa: Case of Rwanda. Available at SSRN 3586622. 2020 Apr 27.
5. WHO, First Case of COVID-19 confirmed in Rwanda.2020 https://www.afro.who.int/ news/first-case-covid-19-confirmed-rwanda accessed on 11th May 2020

6. Rwanda Biomedical Center. 2020 https://www.rbc.gov.rw/fileadmin/user_upload /annoucement/Update\%20on\%20COVID-19\% 2014\%205\%202020\%20eng.jpg Accessed on 28th May 2020

7. WHO recommendation on birth preparedness and complication readiness interventions WHO Reproductive Health Library; Geneva: World Health Organization. 2015 https://extranet. who.int/rhl/topics/improving-health-systemperformance/who-recommendation-birthpreparedness-and-complication-readiness

8. Marangoni $\mathrm{F}$ et al., Maternal diet and nutrient requirements in pregnancy and breastfeeding. An Italian consensus document. Nutrients. 2016 Oct;8(10):629.

9. Smeele $P$, Kalisa $R$, van Elteren $M$, van Roosmalen J, van den Akker T. Birth preparedness and complication readiness among pregnant women admitted in a rural hospital in Rwanda. BMC pregnancy and childbirth. 2018 Dec 1;18(1):190.

10. Koons C. No Hand to Hold: Women Face Labor Alone at Slammed NYC Hospitals Bloomberg (2020)

11. Nick Malherbe. Community psychology and the crisis of care (2020). Journal of Community Psychology 122.

12. World Health Organization (WHO). Rational use of personal protective equipment for coronavirus disease 2019 ( COVID-19). World Heal Organ. 2020

13. Boretti A. Sustainable post Covid19 lockdown strategy through evidence-based policy. Integr J Med Sci. 2020 